Article

\title{
N,P-Codoped Carbon Layer Coupled with MoP Nanoparticles as an Efficient Electrocatalyst for Hydrogen Evolution Reaction
}

\author{
Shuai Wang, Jia Wang, Ping Li, Zexing Wu * and Xien Liu * (1D \\ State Key Laboratory Base of Eco-chemical Engineering, College of Chemistry and Molecular Engineering, \\ Qingdao University of Science \& Technology, Qingdao 266042, China; qustwangshuai@qust.edu.cn (S.W.); \\ 18753363755@163.com (J.W.); qustlipingest@163.com (P.L.) \\ * Correspondence: splswzx@qust.edu.cn (Z.W.); liuxien@qust.edu.cn (X.L.); Tel.: +86-187-6390-9193 (Z.W.); \\ +86-139-6968-0591 (X.L.)
}

Received: 27 June 2018; Accepted: 27 July 2018; Published: 30 July 2018

\begin{abstract}
Efficient electrocatalyst plays a significant role on the development of hydrogen energy. In this work, an N,P-codoped carbon layer coupled with MoP nanoparticles (MoP/NPCs) was prepared through a facile high-temperature pyrolysis treatment. The obtained MoP/NPCs presented efficient activity for hydrogen evolution reaction (HER), with low onset potential of $90 \mathrm{mV}$, and a small Tafel slope $\left(71 \mathrm{mV} \mathrm{dec}^{-1}\right)$, as well as extraordinary stability in acidic electrolyte. This work provides a new facile strategy for the design and synthesis of sustainable and effective molybdenum-based electrocatalysts as alternatives to non-Pt catalysts for HER.
\end{abstract}

Keywords: electrocatalysts; hydrogen evolution reaction; carbon layer; molybdenum phosphide

\section{Introduction}

As is known to all, fossil energy (i.e., oil, natural gas, coal) suffers from excessive consumption with rapidly growing economies, which results in global environmental destruction and energy crisis [1-4]. Researchers have focused on the development of efficient energy devices and green energy like fuel cells to alleviate the increasingly serious environmental pollution and depletion of energy resources [5-7]. With the characteristics of renewability, cleanness, and high energy-density fuel, hydrogen has been extensively studied as a promising alternative energy resource to replace non-renewable fossil fuels prepared by water electrolysis [8-11]. Generally, Pt-based materials have been recognized as the most effective electrocatalyst, as its large cathodic current densities and low overpotential for hydrogen evolution reaction (HER), plays a significant role in water electrolysis [12-17]. However, its high cost and inadequate storage cumbers its wide application. Thus, researchers have devoted a good deal of effort into developing high-activity, low-cost, and relatively abundant electrocatalysts [18-24].

Molybdenum phosphide (MoP) has extensively been investigated for HER, due to its similar electronic structure and excellent catalytic performance for hydrodesulfurization, which have similar reaction processes to HER [25-28]. Schaak et al. [29] synthesized amorphous MoP nanoparticles which exhibited high performance of HER in acid electrolytes. A self-supported electrocatalyst MoP@NPCNFs was developed, and it revealed remarkable catalytic activity for HER [25]. Molybdenum phosphide was also investigated for HER in both acid and alkaline electrolytes [30,31]. However, there still exists room for practical consideration of MoP, as negatively charged $\mathrm{P}$ sites and passive supporters can easily be formed on the surface at high temperatures, which can hinder the reaction process. Thus, it can be seen that there is a challenge to develop well-crystallized MoP nanoparticles as an efficient electrocatalyst for HER. 
Herein, we develop an efficient strategy to form MoP/NPC which exhibit excellent HER performance. The prepared MoP/NPC catalyst exhibits high efficient hydrogen evolution reaction (HER) activity with a low onset potential of $90 \mathrm{mV}$, and a small Tafel slope $\left(71 \mathrm{mV} \mathrm{dec}^{-1}\right)$, as well as extraordinary stability in acidic electrolyte, which demonstrates a new route to prepare sustainable and effective electrocatalysts as alternatives to non-Pt catalysts for HER.

\section{Materials and Methods}

\subsection{Synthesis of Catalysts}

As demonstrated in Scheme 1, MoP/NPCs were synthesized via a two-step route. Primarily, $400 \mathrm{mg}$ of ammonium molybdate (Aladdin, Aladdin Co. LTD, Shanghai, China) was added into $2 \mathrm{~mL}$ phytic acid (50 wt. \%, Sigma-Aldrich, Merck KGaA, Darmstadt, Germany) to form a homogenous solution under continuous ultrasonic blending. Then, acetone $(20 \mathrm{~mL})$ was added to the solution to precipitate metal glue. After, the metal glue was washed with acetone. After that, the glue was transferred into a tube furnace and annealed at $800^{\circ} \mathrm{C}$ for $30 \mathrm{~min}$ with Ar flowing at $150 \mathrm{~mL} / \mathrm{min}$ and at rising rate of $5^{\circ} \mathrm{C} / \mathrm{min}$, followed by a cooling procedure at room temperature under Ar. Here, the black products were collected and washed with $200 \mathrm{~mL} 2 \mathrm{M} \mathrm{HCl}$ under refluxing for $24 \mathrm{~h}$ at $95^{\circ} \mathrm{C}$. Afterwards, the acid solution was filtered, and the black powder deposited on the filter paper was adequately washed with amounts of distilled water. After being dried in a vacuum at $80^{\circ} \mathrm{C}$ for $2 \mathrm{~h}$, the above products were then annealed at $800{ }^{\circ} \mathrm{C}$ for $1 \mathrm{~h}$ with $\mathrm{Ar}$ and $\mathrm{NH}_{3}$, with each gas flowing at $500 \mathrm{~mL} / \mathrm{min}$, and then cooled to room temperature at Ar atmosphere. The resulting catalysts MoP/NPCs were then collected. For comparison, $\mathrm{H}_{2}$ was used as a replacement for $\mathrm{NH}_{3}$ at the end of the process, while the other steps remained consistent, after which MoPON/C catalyst was obtained.
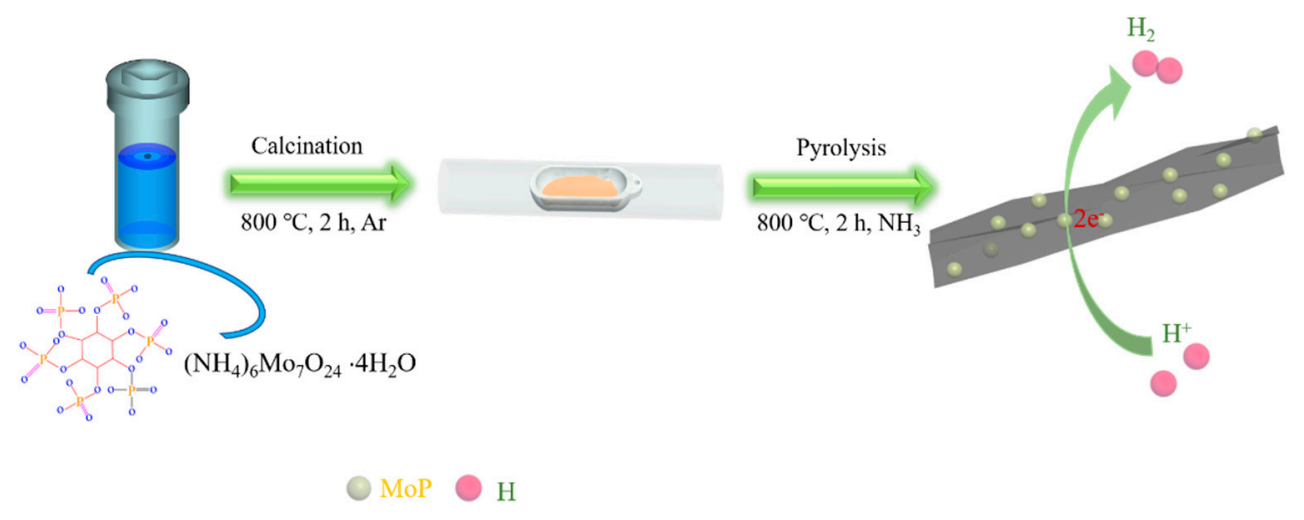

Scheme 1. Schematic illustration for the synthesis of MoP/NPCs.

\subsection{Characterization of Catalysts}

The surface morphologies of different catalyst samples were tested using an S-4800 SEM instrument (Hitachi High-Technology Co., Ltd., Tokyo, Japan) and transmission electron microscopy (TEM). X-ray diffraction (XRD, D/Max2000, Rigaku, Tokyo, Japan) was investigated through radiation of $\mathrm{Cu}-\mathrm{K} \alpha$. X-ray photoelectron spectroscopy (XPS) was measured using Escalab 250 xi (Thermo Scientific, Loughborough, UK), which provided a base pressure of $5 \times 10^{-9}$ Torr radiated from monochromatic $\mathrm{Al} \mathrm{K} \alpha(1486.6 \mathrm{eV})$.

\subsection{Electrochemical Measurements}

Hydrogen evolution reaction activity of the as-prepared catalysts were performed in a standard three-electrode electrochemical cell in argon $0.5 \mathrm{M} \mathrm{H}_{2} \mathrm{SO}_{4}$ solution. A carbon rod and a reversible hydrogen electrode were used as a counter electrode and reference electrode, respectively. The work 
electrode was modified with a catalyst layer by dropping $5 \mu \mathrm{L}$ of catalyst ink on the glassy carbon electrode (GCE) with a diameter of $3 \mathrm{~mm}$. All the linear sweep voltammetry (LSV) curves were obtained at scanning rate of $5 \mathrm{mV} \mathrm{s}^{-1}$. All potentials were calibrated without iR compensation. The frequency of electrochemical impedance spectroscopy (EIS) measurements ranged from 100 to $0.1 \mathrm{~Hz}$ at the potential of $-0.25 \mathrm{~V}$.

\section{Results and Discussion}

\subsection{Characterization of Catalysts}

The microstructure and morphology of the as-prepared catalysts were investigated using scanning electron microscopy (SEM) and transmission electron microscopy (TEM). As shown in Figure 1a,h and Figure S1, the structure of prepared catalysts were composed by irregular nanoparticles. The catalyst of MoPON/C also presented irregular shape from the energy dispersive spectrometer (EDS) elemental mappings (Figure S2). The serious aggregation of MoPON/C (Figures S3,S4) may have resulted in the catalytic performance decline. Figure 1a shows the TEM image of MoP/NPC, revealing that some small nanoparticles were well dispersed on the carbon layer matrix. The prepared catalyst was mainly composed of C, Mo, P, O, and N (Figure 1c-g, Figure S5). The relatively uniform dispersion could expose abundant active sites and rich channels for the diffusion of electrolytes, which is beneficial for the catalytic process [32,33]. As observed from Figure 1i, a high-resolution transmission electron microscopy (HRTEM) image of a MoP/NPC exhibited that the catalysts were coated by graphitic carbon shells, and the lattice plane distance of MoP was $0.27 \mathrm{~nm}$, which can be ascribed to the lattice plane (101) of MoP [32].

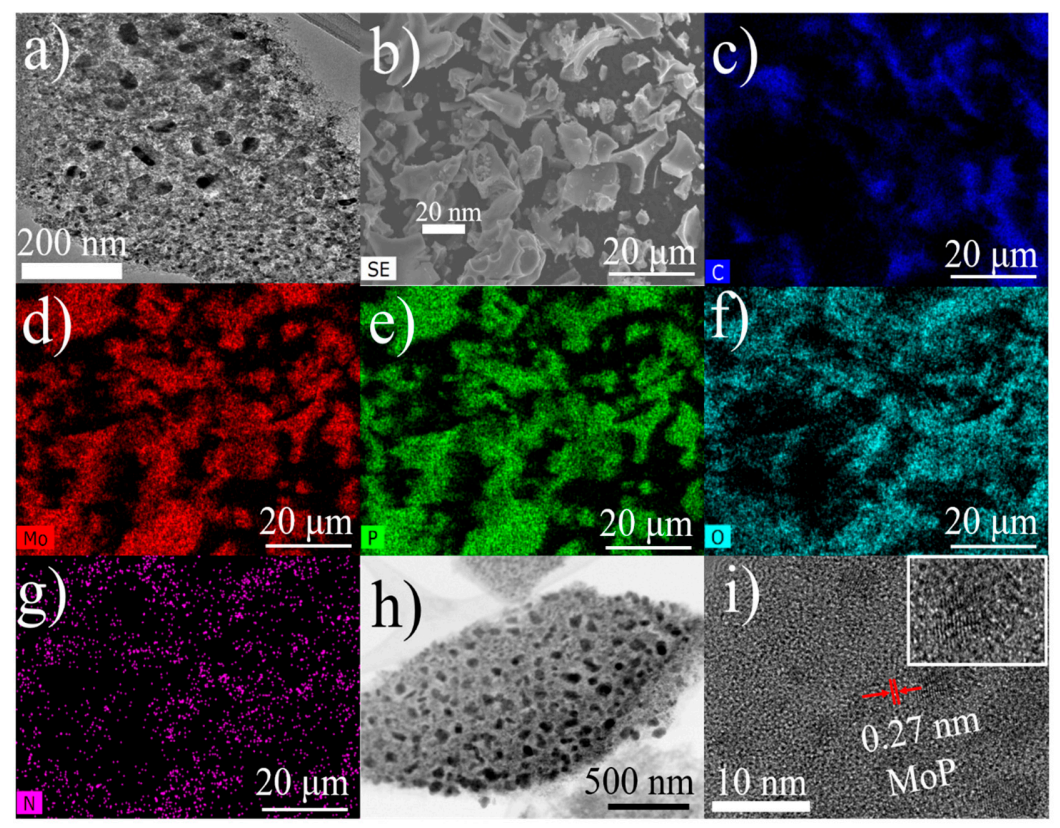

Figure 1. MoP/NPC: (a) TEM; (b) SEM image; (c-g) EDS elemental mappings of C, Mo, P, O, and N; (h) Scanning transmission electron microscopy (STEM) image; (i) HRTEM image (inset: detailed).

X-ray photoelectron spectroscopy (XPS) tests were conducted to investigate the composition and chemical valence of the prepared catalysts. In line with the elemental mappings in Figure $1 c-f, C, M o$, $\mathrm{P}$, and $\mathrm{O}$ were obviously detected in the XPS survey spectrum (Figure 2a). The atomic percentages of C, O, P, and Mo were 66.90, 24.68, 6.38, and 2.14 at. \%, respectively. As detected in Figure 2b, four different peaks at $284.5,285.5,286.8$, and $288.4 \mathrm{eV}$ can be attributed to $\mathrm{C}-\mathrm{C}, \mathrm{C}-\mathrm{P}, \mathrm{C}-\mathrm{N}$, and $\mathrm{O}-\mathrm{C}=\mathrm{O}$, respectively $[34,35]$. The existence of $\mathrm{C}-\mathrm{N}$ demonstrates the heteroatom $\mathrm{N}$-doping in the graphitic 
carbon shells, and the $\mathrm{C}-\mathrm{P}$ might originate from MoP bonded to the graphitic carbon shell [36]. Typically, the Mo 3d peak can be fitted with four regions in Figure 2c, indicating that there were two valence states $(+4,+6)$ for the Mo element in the MoP/NPCs, which confirms the existence of MoP [27]. The high oxidation state of $\mathrm{Mo}^{4+}$ (228.2 and $231.6 \mathrm{eV}$ ) and $\mathrm{Mo}^{6+}(233.2$ and $236.3 \mathrm{eV}$ ) in MoP/NPCs may be caused by the surface oxidation suffering from air contact [32]. For the high-resolution $\mathrm{N}$ 1s spectrum in Figure 2d, three peaks at $398.2 \mathrm{eV}, 399.2 \mathrm{eV}$, and $401.5 \mathrm{eV}$ were assigned to pyridinic $\mathrm{N}$, pyrrolic $\mathrm{N}$, and graphitic $\mathrm{N}$, which was ascribed to the heteroatom $\mathrm{N}$-doping in the graphitic carbon [37]. The peak in the P 2p spectrum (129.7 eV) (Figure 2e) can be assigned to P-Mo which was defined as molybdenum phosphide, and a benefit for the catalytic process. Compared with the high resolution P 2p of MoPON/C shown in Figure S6d, the absence of $\mathrm{P}-\mathrm{Mo}$ in high-resolution P 2p demonstrates the inexistence of MoP. Consequently, MoP-NPC and MoPON/C exhibited different catalytic performance. The peak located at $133.3 \mathrm{eV}$ is the representation of $\mathrm{P}$ bonded to $\mathrm{C}$, further manifesting the connection between MoP and graphitic carbon shell. Another obvious peak at $134.1 \mathrm{eV}$ was ascribed to the surface $\mathrm{P}-\mathrm{O}$ group, which was attributed to the oxidation of catalysts in the air [27]. X-ray diffraction (XRD) was investigated to further confirm the composition of MoP/NPCs. As depicted in Figure $2 \mathrm{f}$, the peaks located at $27.81^{\circ}, 32.03^{\circ}, 43.06^{\circ}, 57.47^{\circ}, 57.81^{\circ}, 64.85^{\circ}, 67.03^{\circ}, 67.52^{\circ}$, and $74.21^{\circ}$ indexed to (001), (100), (101), (110), (002), (111), (200), (102), and (201) facets of pure MoP (JCPDS, No. 24-0771), respectively [32].
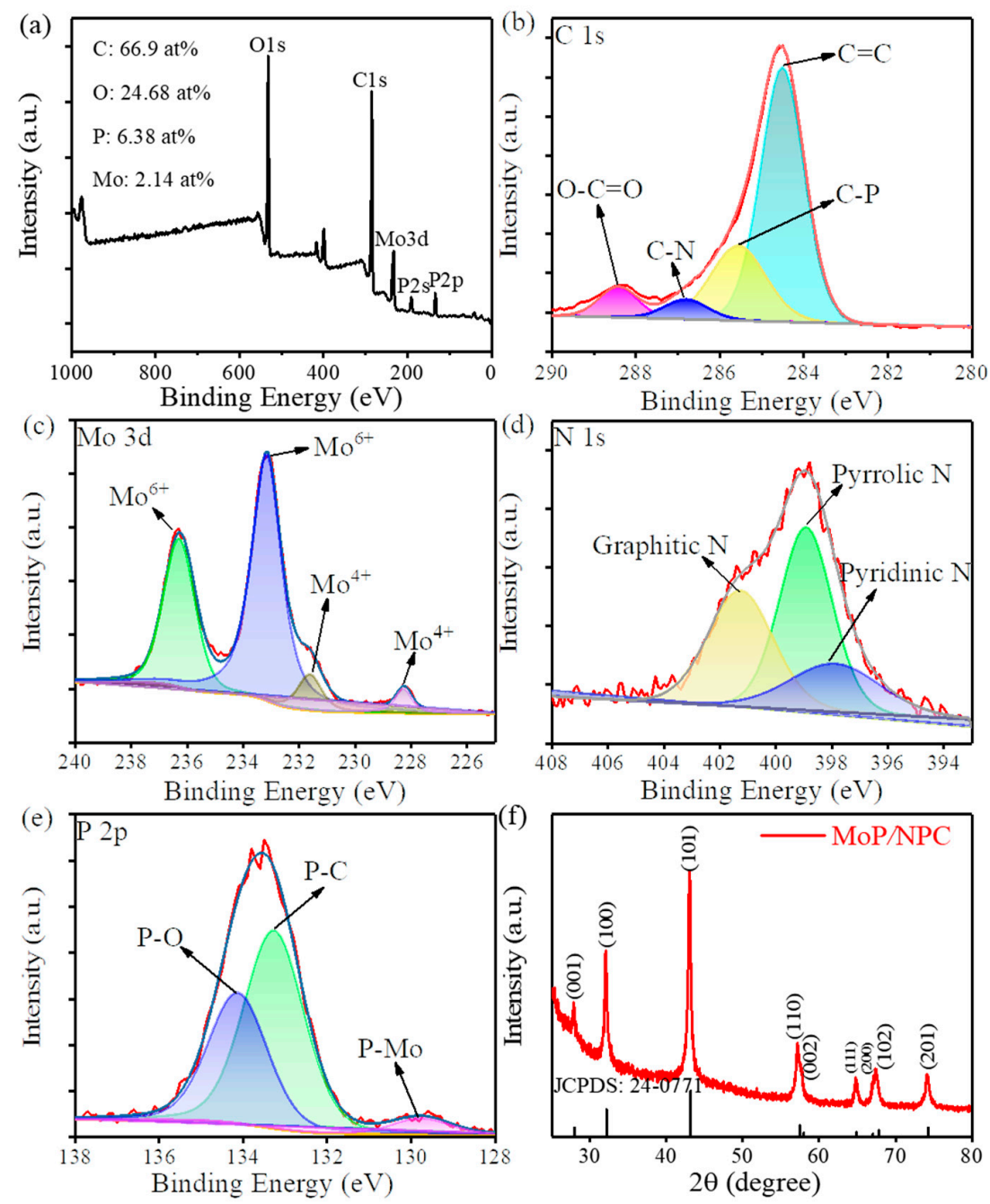

Figure 2. MoP/NPC: (a) XPS survey spectrum; (b) high-resolution XPS spectra of C 1s; (c) Mo 3d; (d) N 1s; (e) P 2p; and (f) XRD pattern. 


\subsection{Electrocatalytic Properties of Catalysts}

Hydrogen evolution reaction electrocatalytic properties of different contents were investigated by a standard three-electrode cell in which the carbon rod was used as counter electrode suppressing interruptions of platinum [38]. Figure 3a,c show the HER polarization curves of MoP/NPC, different dosage of ammonium molybdate $(100,250,400,550 \mathrm{mg})$, and various pyrolysis temperatures $(600,700$, $800,900^{\circ} \mathrm{C}$ ) were determined as objects of study by linear sweep voltammetry (LSV) measurements, respectively. To the best of our knowledge, Tafel slopes are remarkable parameters to suggest HER mechanisms, which is presented in the Tafel Equation $\eta=\mathrm{b} \log j+\mathrm{a}(j$ is the current density, $\mathrm{b}$ is the slope) [29]. Tafel slopes of MoP/NPC-100, 250, 400, $550 \mathrm{mg}$ and MoP/NPC-600, 700, 800, $900{ }^{\circ} \mathrm{C}$ are shown in Figure $3 \mathrm{~b}$,d. Tafel slopes of other conditions were all higher than MoP/NPC-400 $\mathrm{mg}-800{ }^{\circ} \mathrm{C}\left(71 \mathrm{mV} \mathrm{dec}^{-1}\right)$, the linear portions were consistent with the Tafel equation, revealing the HER proceeds through a Volmer-Heyrovsky mechanism. The smaller Tafel slope for MoP/NPC-400 mg, $\mathrm{MoP} / \mathrm{NPC}-800{ }^{\circ} \mathrm{C}$ indicates the better catalytic activity for HER. Overall, the optimal dosage of ammonium molybdate is $400 \mathrm{mg}$, and pyrolysis temperature is $800^{\circ} \mathrm{C}$.
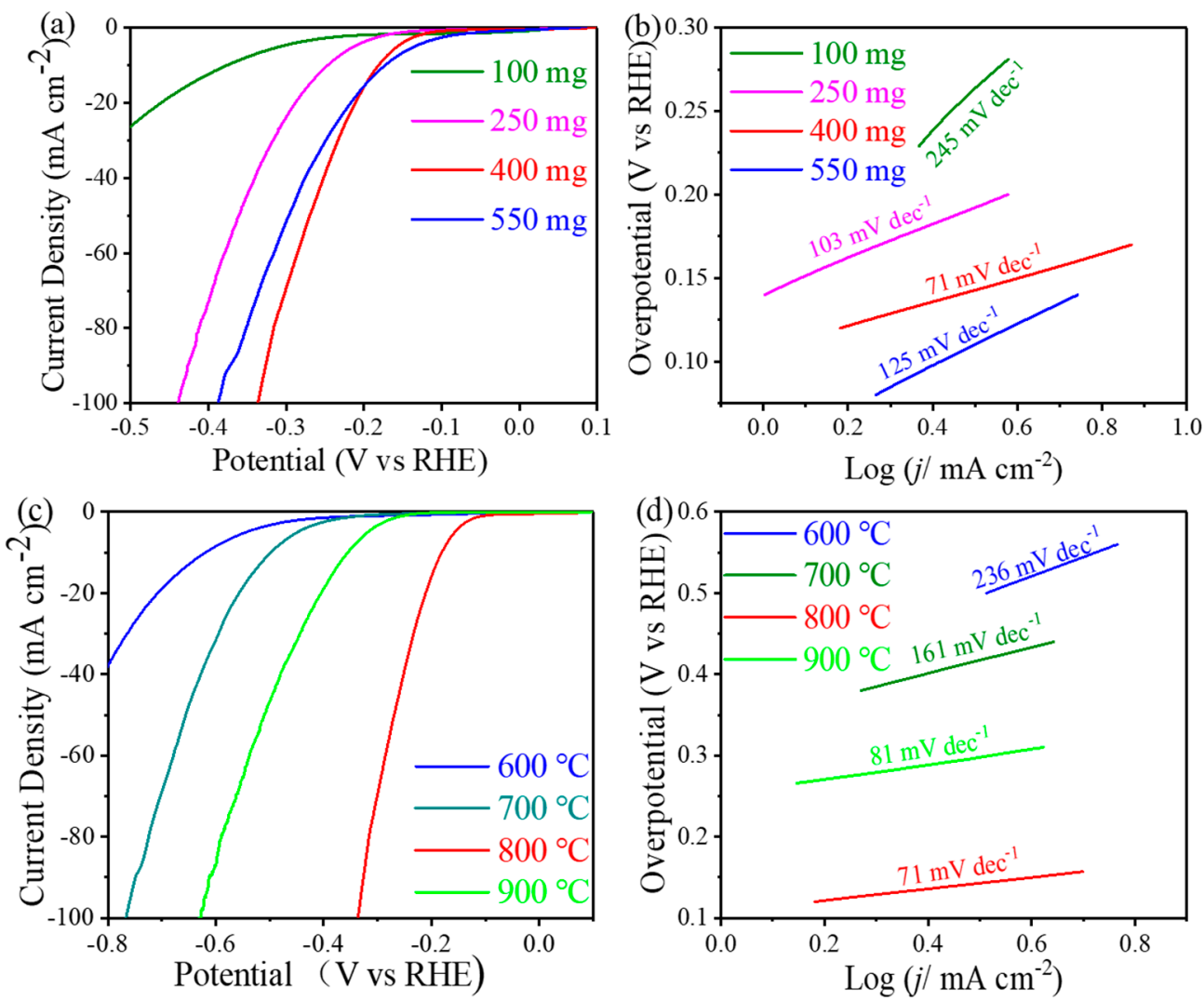

Figure 3. (a) Polarization curves of MoP/NPC-100 mg, $250 \mathrm{mg}, 400 \mathrm{mg}, 550 \mathrm{mg}$ (dosage of ammonium molybdate) in $0.5 \mathrm{M} \mathrm{H}_{2} \mathrm{SO}_{4}$; (b) Tafel plots of MoP/NPC-100 mg, $250 \mathrm{mg}, 400 \mathrm{mg}, 550 \mathrm{mg}$ in $0.5 \mathrm{M} \mathrm{H}_{2} \mathrm{SO}_{4}$; (c) polarization curves of $\mathrm{MoP} / \mathrm{NPC}-600{ }^{\circ} \mathrm{C}, 700{ }^{\circ} \mathrm{C}, 800{ }^{\circ} \mathrm{C}, 900{ }^{\circ} \mathrm{C}$ in $0.5 \mathrm{M} \mathrm{H}_{2} \mathrm{SO}_{4}$; (d) Tafel plots of MoP $/ \mathrm{NPC}-600{ }^{\circ} \mathrm{C}, 700{ }^{\circ} \mathrm{C}, 800{ }^{\circ} \mathrm{C}, 900{ }^{\circ} \mathrm{C}$ in $0.5 \mathrm{M} \mathrm{H}_{2} \mathrm{SO}_{4}$.

Figure 4a shows the HER polarization curves of $\mathrm{Pt} / \mathrm{C}, \mathrm{MoPON} / \mathrm{C}$ and MoP/NPC. It is well known that $\mathrm{Pt} / \mathrm{C}$ with low overpotential and high current density is determined as the superior material for HER [39]. Compared to MoPON/C with an onset potential of $148 \mathrm{mV}$, the MoP/NPC shows the smaller onset potential of $90 \mathrm{mV}\left(1 \mathrm{~mA} \mathrm{~cm}^{-2}\right)$. Overpotentials of $205 \mathrm{mV}$ is needed to conduct a current density of $10 \mathrm{~mA} \mathrm{~cm}^{-2}$ for MoPON/C, demonstrating the relatively inferior HER activities of this catalyst compared with that of MoP/NPC $(180 \mathrm{mV})$. In addition, the current density of MoP/NPC 
is higher than that of MoPON/C at the range of potential. To investigate the HER reaction mechanisms of these catalysts, Tafel plots derived from the polarization curves are shown in Figure $4 \mathrm{~b}$. The Tafel slope is $71 \mathrm{mV} \mathrm{dec}^{-1}$ for MoP/NPC, slightly larger than that of $\mathrm{Pt} / \mathrm{C}\left(37 \mathrm{mV} \mathrm{dec}^{-1}\right)$, confirming the highly efficient kinetics of MoP/NPC for HER, which follows a Volmer-Heyrovsky mechanism [40].
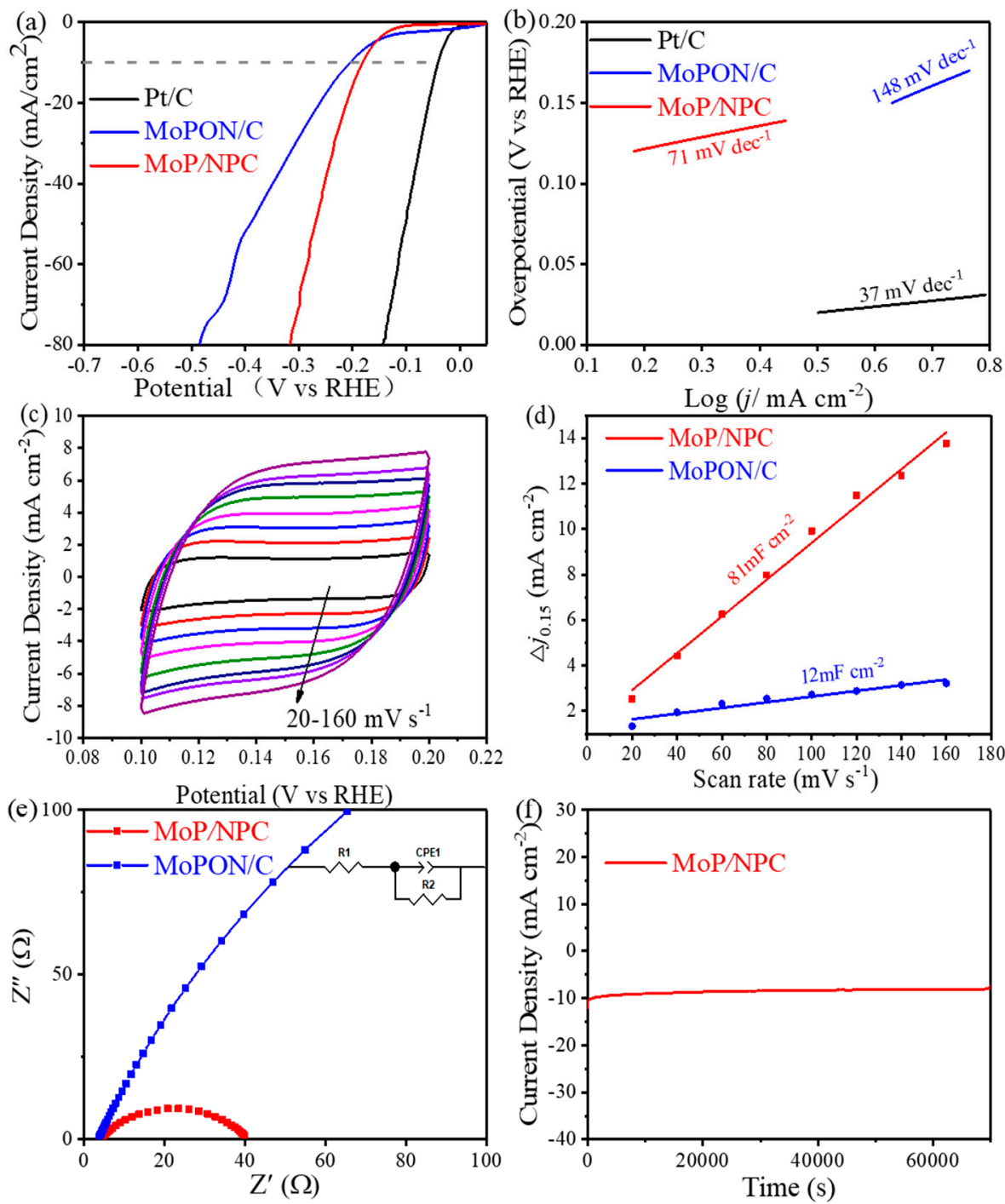

Figure 4. (a) Polarization curves of MoPON/C, MoP/NPC, and Pt/C in $0.5 \mathrm{M} \mathrm{H}_{2} \mathrm{SO}_{4}$; (b) Tafel plots of $\mathrm{MoPON} / \mathrm{C}, \mathrm{MoP} / \mathrm{NPC}$, and $\mathrm{Pt} / \mathrm{C}$ in $0.5 \mathrm{M} \mathrm{H}_{2} \mathrm{SO}_{4}$; (c) $\mathrm{CVs}$ for MoP/NPC with different rates from 20 to $160 \mathrm{mV} \mathrm{s}^{-1}$; (d) the capacitive currents plotted as a function of scan rate; (e) Nyquist plots of electrochemical impedance spectra (EIS) of MoP/NPC and MoPON/C recorded in $0.5 \mathrm{M} \mathrm{H}_{2} \mathrm{SO}_{4}$. Inset: one-time-constant model equivalent circuit used for data fitting of EIS spectra (R1 is the overall series resistance, CPE1 is the constant-phase element and resistance related to surface porosity, R2 is the charge-transfer resistance related to HER process); (f) time-dependent current density curve of $\mathrm{MoP} / \mathrm{NPC}$ under a static overpotential of $0.18 \mathrm{~V}$ for $19 \mathrm{~h}$.

The electrochemical active surface area (ECSA) is regarded as a quantitative index for surface roughness. For that, the cyclic voltammograms (CVs) of MoP/NPC and MoPON/C were measured in the region of 0.1-0.2 V (Figure 3c, Figure S7). As demonstrated in Figure 3d, the capacitance of the double layer $\left(\mathrm{C}_{\mathrm{dl}}\right)$ for $\mathrm{MoP} / \mathrm{NPC}$ was $81 \mathrm{mF} \mathrm{cm}^{-2}$, which was much higher than MoPON/C $\left(12 \mathrm{mF} \mathrm{cm}^{-2}\right)$, indicating a larger ECSA for the MoP/NPC. This phenomenon may be the result of the lattice of MoP, which can expose more electrochemically active sites. Further, electrochemical 
impedance spectroscopy (EIS), which reflects the charge transfer kinetics [41], were also performed. The Nyquist plots in Figure 4e reveal a small charge transfer resistance for MoP/NPC towards the HER process, suggesting the high intrinsic conductivity and faster Faradaic process in HER kinetics of $\mathrm{MoP} / \mathrm{NPC}$. In addition, $\mathrm{i}-\mathrm{t}$ measurements of MoP/NPC over extended periods were conducted at a constant overpotential of $0.18 \mathrm{~V}$. As demonstrated in Figure $4 \mathrm{f}$, the MoP/NPC exhibited an excellent electrocatalytic stability without obvious current loss within $19 \mathrm{~h}$. In conclusion, these results further indicate that the MoP nanoparticles are the main HER active sites.

\section{Conclusions}

In summary, MoP decorated on NPCs as an efficient electrocatalyst for HER was successfully synthesized via annealing a mixture of ammonium molybdate and phytic acid. The MoP/NPC catalyst delivers highly efficient HER activity with a low onset potential of $90 \mathrm{mV}$, and a small Tafel slope $\left(71 \mathrm{mV} \mathrm{dec}^{-1}\right)$, as well as extraordinary stability in acidic electrolyte. Therefore, this work may open up a new strategy for the design and synthesis of sustainable and effective electrocatalysts as alternatives to non-Pt catalysts for HER.

Supplementary Materials: The following are available online at http:/ /www.mdpi.com/1996-1944/11/8/1316/s1, Figure S1: (a) TEM of MoP/NPC, Figure S2: EDS spectra of MoP/NPC, Figure S3: SEM of MoPON/C, Figure S4: TEM of MoPON/C; Figure S5: EDS spectra of MoP/NPC, Figure S6: MoPON/C: (a) XPS survey spectrum; (b-e) high-resolution XPS spectra of Mo 3d, C 1s, P 2p, and N 1s, Figure S7: CVs of MoPON/C in the region of $0.10-0.20 \mathrm{~V}$ (vs. RHE).

Author Contributions: Writing_-Original Draft Preparation, S.W.; Software and Investigation, J.W.; Visualization, P.L.; Writing—Review \& Editing, Z.W.; Project Administration, X.L.

Funding: This research was funded by the Natural Science Foundation of Shandong Province of China (ZR2017MB054); The Key Research and Development Program of Shandong Province (2018GGX104001). Doctoral Fund of QUST (010022873, 0100229001); and Taishan Scholar Program of Shandong Province, China (ts201712045).

Conflicts of Interest: The authors declare no conflict of interest. The funders had no role in the design of the study; in the collection, analyses, or interpretation of data; in the writing of the manuscript, and in the decision to publish the results.

\section{References}

1. Liu, J.; Liu, Y.; Liu, N.Y.; Han, Y.Z.; Zhang, X.; Huang, H.; Lifshitz, Y.; Lee, S.T.; Zhong, J.; Kang, Z.H. Metal-free efficient photocatalyst for stable visible water splitting via a two-electron pathway. Science 2015, 347, 970-974. [CrossRef] [PubMed]

2. Roger, I.; Shipman, M.A.; Symes, M.D. Earth-abundant catalysts for electrochemical and photoelectrochemical water splitting. Nat. Rev. Chem. 2017, 1, 0003. [CrossRef]

3. Hu, C.; Dai, L. Multifunctional carbon-based metal-free electrocatalysts for simultaneous oxygen reduction, oxygen evolution, and hydrogen evolution. Adv. Mater. 2017, 29, 1604942. [CrossRef] [PubMed]

4. Huang, Y.; Gong, Q.; Song, X.; Feng, K.; Nie, K.; Zhao, F.; Wang, Y.; Zeng, M.; Zhong, J.; Li, Y. $\mathrm{Mo}_{2} \mathrm{C}$ nanoparticles dispersed on hierarchical carbon microflowers for efficient electrocatalytic hydrogen evolution. ACS Nano 2016, 10, 11337-11343. [CrossRef] [PubMed]

5. Shi, Z.; Wang, Y.; Lin, H.; Zhang, H.; Shen, M.; Xie, S.; Zhang, Y.; Gao, Q.; Tang, Y. Porous nanoMoC@graphite shell derived from a MOFs-directed strategy: An efficient electrocatalyst for the hydrogen evolution reaction. J. Mater. Chem. A 2016, 4, 6006-6013. [CrossRef]

6. Chen, Y.Y.; Zhang, Y.; Jiang, W.J.; Zhang, X.; Dai, Z.; Wan, L.J.; Hu, J.S. Pomegranate-like N,P-doped $\mathrm{Mo}_{2} \mathrm{C} @ \mathrm{C}$ nanospheres as highly active electrocatalysts for alkaline hydrogen evolution. ACS Nano 2016, 10, 8851-8860. [CrossRef] [PubMed]

7. Wang, X.D.; Xu, Y.F.; Rao, H.S.; Xu, W.J.; Chen, H.Y.; Zhang, W.X.; Kuang, D.B.; Su, C.Y. Novel porous molybdenum tungsten phosphide hybrid nanosheets on carbon cloth for efficient hydrogen evolution. Energy Environ. Sci. 2016, 9, 1468-1475. [CrossRef] 
8. Liu, Z.; Fu, G.; Li, J.; Liu, Z.; Xu, L.; Sun, D.; Tang, Y. Facile synthesis based on novel carbon-supported cyanogel of structurally ordered $\mathrm{Pd}_{3} \mathrm{Fe} / \mathrm{C}$ as electrocatalyst for formic acid oxidation. Nano Res. 2018, 1-11. [CrossRef]

9. Guo, J.; Wang, J.; Wu, Z.; Lei, W.; Zhu, J.; Xia, K.; Wang, D. Controllable synthesis of molybdenum-based electrocatalysts for a hydrogen evolution reaction. J. Mater. Chem. A 2017, 5, 4879-4885. [CrossRef]

10. Liao, H.; Wei, C.; Wang, J.; Fisher, A.; Sritharan, T.; Feng, Z.; Xu, Z.J. A multisite strategy for enhancing the hydrogen evolution reaction on a nano-Pd surface in alkaline media. Adv. Energy Mater. 2017, 7, 1701129. [CrossRef]

11. Yu, J.; Zhou, W.; Xiong, T.; Wang, A.; Chen, S.; Chu, B. Enhanced electrocatalytic activity of Co@N-doped carbon nanotubes by ultrasmall defect-rich $\mathrm{TiO}_{2}$ nanoparticles for hydrogen evolution reaction. Nano Res. 2017, 10, 2599-2609. [CrossRef]

12. Ji, L.; Wang, J.; Guo, L.; Chen, Z. In situ $\mathrm{O}_{2}$-emission assisted synthesis of molybdenum carbide nanomaterials as an efficient electrocatalyst for hydrogen production in both acidic and alkaline media. J. Mater. Chem. A 2017, 5, 5178-5186. [CrossRef]

13. Li, J.; Zheng, G. One-dimensional earth-abundant nanomaterials for water-splitting electrocatalysts. Adv. Sci. 2017, 4, 1600380. [CrossRef] [PubMed]

14. Lv, C.; Huang, Z.; Yang, Q.; Wei, G.; Chen, Z.; Humphrey, M.G.; Zhang, C. Ultrafast synthesis of molybdenum carbide nanoparticles for efficient hydrogen generation. J. Mater. Chem. A 2017, 5, 22805-22812. [CrossRef]

15. Miao, M.; Pan, J.; He, T.; Yan, Y.; Xia, B.Y.; Wang, X. Molybdenum carbide-based electrocatalysts for hydrogen evolution reaction. Chem. Eur. J. 2017, 23, 10947-10961. [CrossRef] [PubMed]

16. Anjum, M.A.R.; Lee, M.H.; Lee, J.S. BCN network-encapsulated multiple phases of molybdenum carbide for efficient hydrogen evolution reactions in acidic and alkaline media. J. Mater. Chem. A 2017, 5, 13122-13129. [CrossRef]

17. Eftekhari, A. Electrocatalysts for hydrogen evolution reaction. Int. J. Hydrogen Energy 2017, 42, 11053-11077. [CrossRef]

18. Xu, J.; Cui, J.; Guo, C.; Zhao, Z.; Jiang, R.; Xu, S.; Zhuang, Z.; Huang, Y.; Wang, L.; Li, Y. Ultrasmall $\mathrm{Cu}_{7} \mathrm{~S}_{4} @ \mathrm{MoS}_{2}$ hetero-nanoframes with abundant active edge sites for ultrahigh-performance hydrogen evolution. Angew. Chem. Int. Ed. 2016, 55, 6502-6505. [CrossRef] [PubMed]

19. Fan, X.J.; Peng, Z.W.; Ye, R.Q.; Zhou, H.Q.; Guo, X. $\mathrm{M}_{3} \mathrm{C}$ (M: Fe, Co, Ni) Nanocrystals Encased in Graphene Nanoribbons: An Active and Stable Bifunctional Electrocatalyst for Oxygen Reduction and Hydrogen Evolution Reactions. ACS Nano 2015, 9, 7407-7418. [CrossRef] [PubMed]

20. Zhang, Y.; Li, P.; Yang, X.; Fa, W.; Ge, S. High-efficiency and stable alloyed nickel based electrodes for hydrogen evolution by seawater splitting. J. Alloys Compd. 2018, 732, 248-256. [CrossRef]

21. Ito, Y.; Cong, W.; Fujita, T.; Tang, Z.; Chen, M. High catalytic activity of nitrogen and sulfur co-doped nanoporous graphene in the hydrogen evolution reaction. Angew. Chem. Int. Ed. 2015, 54, 2131-2136. [CrossRef] [PubMed]

22. Pi, M.; Zhang, D.; Wang, S.; Chen, S. Enhancing electrocatalytic hydrogen evolution of $\mathrm{WP}_{2}$ three-dimensional nanowire arrays via Mo doping. Mater. Lett. 2018, 213, 315-318. [CrossRef]

23. Xiong, J.; Li, J.; Shi, J.; Zhang, X.; Suen, N.-T.; Liu, Z.; Huang, Y.; Xu, G.; Cai, W.; et al. In situ engineering of double-phase interface in $\mathrm{Mo} / \mathrm{Mo}_{2} \mathrm{C}$ heteronanosheets for boosted hydrogen evolution reaction. ACS Energy Lett. 2018, 3, 341-348. [CrossRef]

24. Lin, H.; Liu, N.; Shi, Z.; Guo, Y.; Tang, Y.; Gao, Q. Cobalt-doping in molybdenum-carbide nanowires toward efficient electrocatalytic hydrogen evolution. Adv. Funct. Mater. 2016, 26, 5590-5598. [CrossRef]

25. Wang, M.; Ye, C.; Xu, M.; Bao, S. MoP nanoparticles with a P-rich outermost atomic layer embedded in $\mathrm{N}$-doped porous carbon nanofibers: Self-supported electrodes for efficient hydrogen generation. Nano Res. 2018, 1-7. [CrossRef]

26. Deng, C.; Ding, F.; Li, X.; Guo, Y.; Ni, W.; Yan, H.; Sun, K.; Yan, Y.-M. Templated-preparation of a three-dimensional molybdenum phosphide sponge as a high performance electrode for hydrogen evolution. J. Mater. Chem. A 2016, 4, 59-66. [CrossRef]

27. Wu, Z.; Wang, J.; Liu, R.; Xia, K.; Xuan, C.; Guo, J.; Lei, W.; Wang, D. Facile preparation of carbon sphere supported molybdenum compounds (P, C and S) as hydrogen evolution electrocatalysts in acid and alkaline electrolytes. Nano Energy 2017, 32, 511-519. [CrossRef] 
28. Pan, Y.; Lin, Y.; Liu, Y.; Liu, C. A novel CoP/MoS $2-\mathrm{CNTs}$ hybrid catalyst with Pt-like activity for hydrogen evolution. Catal. Sci. Technol. 2016, 6, 1611-1615. [CrossRef]

29. McEnaney, J.M.; Crompton, J.C.; Callejas, J.F.; Popczun, E.J.; Biacchi, A.J.; Lewis, N.S.; Schaak, R.E. Amorphous molybdenum phosphide nanoparticles for electrocatalytic hydrogen evolution. Chem. Mater. 2014, 26, 4826-4831. [CrossRef]

30. Wu, Z.; Wang, J.; Zhu, J.; Guo, J.; Xiao, W.; Xuan, C.; Lei, W.; Wang, D. Highly efficient and stable MoP-rGO nanoparticles as electrocatalysts for hydrogen evolution. Electrochim. Acta 2017, 232, 254-261. [CrossRef]

31. Wu, Z.; Wang, J.; Xia, K.; Lei, W.; Liu, X.; Wang, D. MoS ${ }_{2}-$ MoP heterostructured nanosheets on polymer-derived carbon as an electrocatalyst for hydrogen evolution reaction. J. Mater. Chem. A 2018, 6, 616-622. [CrossRef]

32. Zhang, L.N.; Li, S.H.; Tan, H.Q.; Khan, S.U.; Ma, Y.Y.; Zhang, H.Y.; Wang, Y.H.; Li, Y.G. MoP/Mo $2 \mathrm{C} @$ C: A New Combination of Electrocatalysts for Highly Efficient Hydrogen Evolution over the Entire pH Range. ACS Appl. Mater. Interfaces 2017, 9, 16270-16279. [CrossRef] [PubMed]

33. Ma, Y.-Y.; Wu, C.-X.; Feng, X.-J.; Tan, H.-Q.; Yan, L.-K.; Liu, Y.; Kang, Z.-H.; Wang, E.-B.; Li, Y.-G. Highly efficient hydrogen evolution from seawater by a low-cost and stable CoMoP@C electrocatalyst superior to Pt/C. Energy Environ. Sci. 2017, 10, 788-798. [CrossRef]

34. Ji, L.; Wang, J.; Teng, X.; Dong, H.; He, X.; Chen, Z. N,P-doped molybdenum carbide nanofibers for efficient hydrogen production. ACS Appl. Mater. Interfaces 2018, 10, 14632-14640. [CrossRef] [PubMed]

35. Yan, H.; Tian, C.; Wang, L.; Wu, A.; Meng, M.; Zhao, L.; Fu, H. Phosphorus-modified tungsten nitride/reduced graphene oxide as a high-performance, non-noble-metal electrocatalyst for the hydrogen evolution reaction. Angew. Chem. Int. Ed. 2015, 54, 6325-6329. [CrossRef] [PubMed]

36. Feng, L.; Chen, X.; Cao, Y.; Chen, Y.; Wang, F.; Chen, Y.; Liu, Y. Pyridinic and pyrrolic nitrogen-rich ordered mesoporous carbon for efficient oxygen reduction in microbial fuel cells. RSC Adv. 2017, 7, 14669-14677. [CrossRef]

37. Chen, Z.; Song, Y.; Cai, J.; Zheng, X.; Han, D.; Wu, Y.; Zang, Y.; Niu, S.; Liu, Y.; Zhu, J.; et al. Tailoring the d-band centers enables $\mathrm{Co}_{4} \mathrm{~N}$ nanosheets to be highly active for hydrogen evolution catalysis. Angew. Chem. Int. Ed. 2018, 57, 5076-5080. [CrossRef] [PubMed]

38. Wang, M.Q.; Ye, C.; Liu, H.; Xu, M.; Bao, S.J. Nanosized metal phosphides embedded in nitrogen-doped porous carbon nanofibers for enhanced hydrogen evolution at all $\mathrm{pH}$ values. Angew. Chem. Int. Ed. 2018, 57, 1963-1967. [CrossRef] [PubMed]

39. Hou, Y.; Wen, Z.; Cui, S.; Ci, S.; Mao, S.; Chen, J. An advanced nitrogen-doped graphene/cobalt-embedded porous carbon polyhedron hybrid for efficient catalysis of oxygen reduction and water splitting. Adv. Funct. Mater. 2015, 25, 872-882. [CrossRef]

40. Ling, T.; Yan, D.Y.; Wang, H.; Jiao, Y.; Hu, Z.; Zheng, Y.; Zheng, L.; Mao, J.; Liu, H.; Du, X.-W.; et al. Activating cobalt(ii) oxide nanorods for efficient electrocatalysis by strain engineering. Nat. Commun. 2017, 8, 1509. [CrossRef] [PubMed]

41. Gordon, I.A.J.; Grugeon, S.; Takenouti, H.; Tribollet, B.; Armand, M.; Davoisne, C.; Débart, A.; Laruelle, S. Electrochemical impedance spectroscopy response study of a commercial graphite-based negative electrode for li-ion batteries as function of the cell state of charge and ageing. Electrochim. Acta 2017, 223, 63-73. [CrossRef]

(C) 2018 by the authors. Licensee MDPI, Basel, Switzerland. This article is an open access article distributed under the terms and conditions of the Creative Commons Attribution (CC BY) license (http://creativecommons.org/licenses/by/4.0/). 